Rev. Elet. em Gestão, Educação e Tecnologia Ambiental (e-ISSN: 2236-1170)

\title{
ANÁLISE MICROBIOLÓGICA DE AMOSTRAS DE ÁGUA DE POÇOS RASOS LOCALIZADOS NO MUNICÍPIO DE BURITIS, REGIÃO DO VALE DO JAMARI, RONDÔNIA, AMAZÔNIA OCIDENTAL.
}

\author{
Renato André Zan ${ }^{1}$, Alessandro Lima Costa², Janice Barbieri Costa ${ }^{3}$, \\ Dionatas Ulises de Oliveira Meneguetti ${ }^{4}$ \\ ${ }^{1}$ renato-zan@hotmail.com, Químico, Mestre em Química, Docente e Coordenador de Pesquisa e Iniciação Científica \\ da (FAEMA), Faculdade de Educação e Meio Ambiente \\ 2 lohamiariquemes@hotmail.com, Discente do Curso de Graduação em Farmácia Generalista da Faculdade de \\ Educação e Meio Ambiente (FAEMA) \\ 3 lohamiariquemes@hotmail.com, Discente do Curso de Graduação em Farmácia Generalista da Faculdade de \\ Educação e Meio Ambiente (FAEMA) \\ ${ }^{4}$ dionatasmeneguetti@hotmail.com, Biólogo, Mestre em Genética e Toxicologia Aplicada, Docente e Coordenador de \\ Extensão da (FAEMA), Faculdade de Educação e Meio Ambiente
}

http://dx.doi.org/10.5902/223611707293

\section{RESUMO}

Mais de um bilhão de pessoas do mundo carecem de água doce, e o consumo humano deverá duplicar a cada vinte e cinco anos aproximadamente, sendo que as águas subterrâneas provenientes de poços rasos são cada vez mais utilizadas para o consumo humano e a associação de vários problemas de saúde principalmente em pessoas idosas e crianças menores de cinco anos. O presente estudo teve como objetivo realizar a análise microbiológica em água de poço da zona urbana do município de Buritis, Rondônia, Brasil. Foram coletadas e analisadas 30 (trinta) amostras de água por meio de cultura em cartela em forma de gel desidratado. Constatou-se a contaminação do lençol freático analisando por coliformes totais e fecais, não atendendo os padrões de potabilidade recomendado na Portaria 518/04, para o consumo humano representando um risco para a saúde.

Palavras-chave: Água de poço, análise microbiológica,e Amazônia ocidental.

\begin{abstract}
More than one billion people in the world lack of fresh water, and human consumption is expected to double every twenty-five years, and groundwater from shallow wells are increasingly used for human consumption and the association of various problems health especially in the elderly and children under five. The present study aims to perform microbiological analysis of well water in the urban area of Buritis, Rondônia, Brazil. Were collected and analyzed thirty (30) samples of water by means of culture in dish in form of dehydrated gel. It was found to groundwater contamination by total and fecal coliforms, not meeting the standards of potability recommended in Regulation 518/04 for the human consumption representing a risk to health.
\end{abstract}

Keywords: Wellwater, microbiological analysis and Western Amazon. 
Rev. Elet. em Gestão, Educação e Tecnologia Ambiental (e-ISSN: 2236-1170)

\section{INTRODUÇÃO}

Mais de 1,3 bilhões de pessoas do mundo carecem de água doce no mundo, e o consumo humano deverá duplicar a cada 25 (vinte e cinco) anos aproximadamente (MACHADO, 2003), esses números ainda são maiores quando se trata de água potável, que é toda aquela que pode ser consumida sem riscos a saúde humana e rejeição por suas características organolépticas (BRASIL, 2006).

Entre as diferentes maneiras de se adquirir água, podemos destacar as águas subterrâneas provenientes de poços rasos, essas que tem sido cada vez mais utilizada para o consumo humano (BLANK et al., 2010), pois além de ser economicamente viável é uma fonte de abastecimento indispensável para as populações que não tem acesso a rede pública de abastecimento de água (FREITAS et al., 2001 ), esses poços têm diâmetro mínimo de 90 centímetros, geralmente entre 10 de 20 metros de profundidade, destinado ao abastecimento individual ou coletivo, podendo obter de dois a três mil litros de água por dia (MANUAL, 2012).

Esse tipo de abastecimento gera preocupação, principalmente por ficarem muito próximo de locais onde são descartados dejetos humanos, sendo a coleta de amostras de água em campo importante para a realização de programa de monitoramento de qualidade de água (CETESB, 1987).

Doenças que podem ser propagadas pela água como, por exemplo, hepatite $A$ e Poliomielite, doenças diarréicas como verminoses, amebíase, giardíase, cólera, febre tifóide, salmonelose (FREITAS et al., 2001 ). A poluição dos corpos hídricos indica que as águas não estão sendo utilizadas corretamente, e que uma das fontes de contaminação que altera a qualidade da água são os esgotos domésticos (ZAMPIERON et al., 2012), isso é preocupante, pois o consumo de água contaminada por microrganismos tem sido associado a vários problemas de saúde, principalmente em pessoas que tem baixa resistência como idosos e crianças menores de cinco anos (SILVA et al., 2003).

Devido à diversidade de microrganismos patogênicos de origem fecal existente na água e a quase impossibilidade de avaliar a presença de todos, a escolha de um indicador microrganismo foi objeto de processo histórico realizado pela comunidade científica internacional (BRASIL, 2006). A avaliação de cada tipo de microrganismo exige uma metodologia diferente, a ausência ou presença de um patógeno não exclui a presença de outros (DUARTE, 2011).

Por definição o grupo coliforme são todas as bactérias aeróbias ou anaeróbias facultativas, gram negativas, não formadores de esporos, forma de bastonete, fermentam lactose com formação de gás no prazo de 48 horas a 35 C, que incluem aos gêneros Escherichia, Enterobacter, Citrobactere Klebsiella (BRASIL, 2012).

As bactérias do grupo coliformes servem como indicador de contaminação fecal, pois habitam normalmente o intestino de homens e animais, está presente também em grande quantidade nos esgotos domésticos, pois cada pessoa elimina bilhões destas bactérias diariamente, desta forma, havendo contaminação da água por esgotos domésticos, é grande a chance de encontrar coliformes em qualquer amostra de água (BRASIL, 2006).

O presente estudo objetivou realizar análise microbiológica de amostras de água de poço rasos localizados na zona urbana do município de Buritis, Rondônia, Brasil. 


\section{MATERIAIS E MÉTODOS}

\section{Área de estudo}

O município de Buritis (Figura 1) fica localizado há $328 \mathrm{~km}$ da capital Porto Velho, na região noroeste do Estado de Rondônia, apresenta área total de $3.265 .8 \mathrm{Km}^{2}$; com população de 32.383 habitantes, sendo 18.122 é a população urbana, não possui rede geral de distribuição de água e nenhum serviço de saneamento básico (BRASIL, 2010).

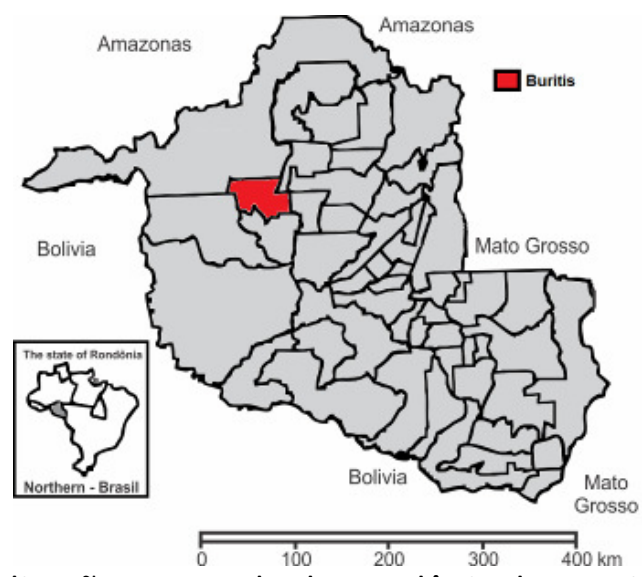

Figura 1. Localização no estado de Rondônia do Município de Buritis

\section{oleta das amostras}

O município foi divido em seis blocos (Figura 2), em cada bloco seriam coletadas cinco amostras, mas devido um equívoco onde no mapa municipal mostra o Bairro ou Setor 11 no bloco 1 , onde na verdade se trata de um recente loteamento e não se encontra nenhuma residência, as coletas que seriam realizadas no bloco 1 , foram transferidas para os blocos 2 e 5 , regiões essas onde se concentram o maior número de residências.

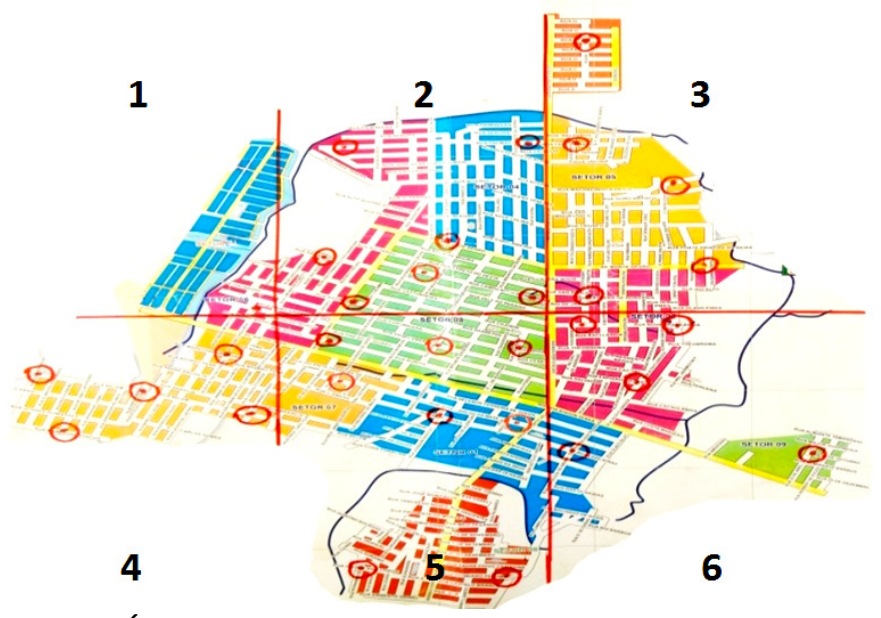

Figura 2. Área de estudo: divisão em bloco do município de Buritis. 
O bloco 2, corresponde aos Bairros ou Setores 03, 04 e 06; bloco 3 (três), corresponde aos Setores 02, 05 e 10; bloco 4 (quatro), corresponde ao Setor 07; bloco 5 (cinco), corresponde aos Setores 01, 03, 07 e 08; bloco 6 (seis), corresponde aos Setores 01, 02 e 09.

Foram realizadas duas coletas no mês de Outubro de 2012, no intervalo de quatro dias entre as coletas, as condições meteorológicas favoráveis sem chuva nas últimas 24 horas nos dias das coletas. As amostras de água foram provenientes de trinta poços rasos da zona urbana do município de Buritis.

As residências foram selecionadas em pontos, conforme distribuição no mapa, no perímetro urbano de Buritis, no intuito de abranger o centro e as extremidades dos blocos, onde a escolha da residência é a mais próxima do ponto identificado no mapa, onde a primeira residência escolhida aleatoriamente, e a casa seguinte escolhida ao ponto mais próximo da primeira coleta.

As amostras foram acondicionadas em garrafas plásticas de $350 \mathrm{ml}$, sendo preenchido aproximadamente com $250 \mathrm{ml}$, devidamente identificadas e esterilizadas com ozônio $\left(\mathrm{O}_{3}\right)$ concentração 2 CPM (Concentração Partes por Milhão), utilizando técnica: Procedimento para coleta de amostras de água (CETESB, 1987), observando todo o cuidado de higiene e assepsia da coleta, realizada com álcool $70 \%$, da tubulação que sai diretamente do poço, sendo deixado escorrer a água por cinco minutos, durante a coleta foi utilizado uma chama com algodão embebido com álcool próximo do frasco coletor, que após a coleta foi fechado imediatamente e recebeu um papel protetor esterilizado com álcool $70 \%$ fixado no gargalo, sendo submetidas à refrigeração em caixa térmica e enviadas para o laboratório físico-químico da Faculdade de Educação e Meio Ambiente - FAEMA.

\section{Análise microbiológica}

As análises foram feitas no mesmo dia das coletas, através do Kit microbiológico Colipaper, cartela com meio de cultura em forma de gel desidratado que detecta e quantifica a presença de coliformes fecais, totais e Salmonella, seguindo os passos descritos:

A- Retirou-se a cartela microbiológica tocando apenas acima do picote (Figura $3 \mathrm{~A}$ );

B- Imergiu-se a cartela na amostra e aguardou-se umedecer, depois se retirou o excesso de água (Figura $3 \mathrm{~B}$ ).

C- Recolocou-se a cartela na embalagem plástica e retirou-se a parte do picote sem tocar no restante, levado a estufa por 15 horas à temperatura de 36ㅇ a 37으 (Figura $3 \mathrm{C}$ ).

D- Realizou-se a leitura (Figura 3 D).

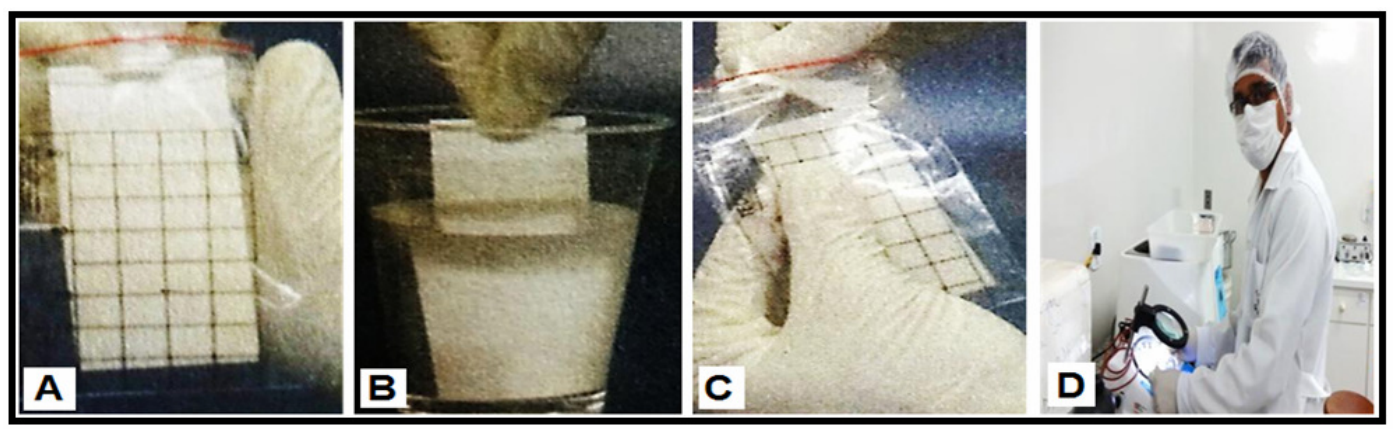

Figura 3: Etapas da análise Microbiológica. 
Rev. Elet. em Gestão, Educação e Tecnologia Ambiental (e-ISSN: 2236-1170)

\section{RESULTADOS E DISCUSSÃO}

Neste estudo a Salmonella apresentou $100 \%$ de ausência nas amostras de água analisadas, por isto não sendo mencionada na figura e tabelas.

Dentro do estudo realizado nos dias 16 e 21 de Outubro de 2012, respectivamente, foram detectadas a presença e ausência de coliformes fecais e totais nas amostras de água de poços rasos da zona urbana do município de Buritis, conforme tabelas 1, 2, 3, 4 e 5.

Tabela 1- Resultados análise de coliforme fecal e total, realizado no bloco 2.

\begin{tabular}{|c|c|c|c|c|c|}
\hline $\begin{array}{c}\text { 19 Coleta } \\
\text { Dia }\end{array}$ & $\begin{array}{c}\text { Portaria } \\
\text { 518/04(V.P.M) }\end{array}$ & $\begin{array}{c}\text { Portaria } \\
\text { 518/04(V.P.M) }\end{array}$ & $\begin{array}{c}\text { 2a Coleta } \\
\text { Dia }\end{array}$ & $\begin{array}{c}\text { Portaria } \\
\text { 518/04(V.P.M) }\end{array}$ & $\begin{array}{c}\text { Portaria } \\
\text { 518/04(V.P.M) }\end{array}$ \\
\hline $16 / 10 / 2012$ & $\begin{array}{c}\text { Ausência/100 ml } \\
\text { C.FECAL }\end{array}$ & $\begin{array}{c}\text { Ausência/100 ml } \\
\text { C. TOTAL }\end{array}$ & $21 / 10 / 2012$ & $\begin{array}{c}\text { Ausência/100 ml } \\
\text { C.FECAL }\end{array}$ & $\begin{array}{c}\text { Ausência } / 100 \mathrm{ml} \\
\text { C. TOTAL }\end{array}$ \\
\hline Amostra 01 & 100 UFC/100 ml & 2900 UFC/100 ml & Amostra 01 & 300 UFC /100 ml & 1400 UFC/100 m \\
\hline Amostra 02 & 100 UFC/100 ml & 1300 UFC/100 ml & Amostra 02 & & 1200 UFC/100 m \\
\hline Amostra 03 & 100 UFC/100 ml & 1800 UFC/100 ml & Amostra 03 & 300 UFC /100 ml & 1700 UFC/100 m \\
\hline Amostra 04 & 1200 UFC/100 ml & $2400 \mathrm{UFC} / 100 \mathrm{ml}$ & Amostra 04 & & 1000 UFC/100 m \\
\hline Amostra 05 & 400 UFC/100 ml & 2000 UFC/100 ml & Amostra 05 & 200 UFC/100 ml & 2500 UFC/100 m \\
\hline Amostra 06 & 100 UFC/100 ml & 700 UFC/100 ml & Amostra 06 & & 300 UFC/100 ml \\
\hline Amostra 07 & 200 UFC/100 ml & 800 UFC/100 ml & Amostra 07 & $400 \overline{U F C / 100} \mathrm{ml}$ & 800 UFC/100 ml \\
\hline
\end{tabular}

V.P.M: valor máximo permitido. UFC/ml: unidade formadora de colônia por mililitro.

Tabela 2- Resultados análise de coliforme fecal e total, realizado no bloco 3.

\begin{tabular}{|c|c|c|c|c|c|}
\hline $\begin{array}{l}\text { 19. Coleta } \\
\text { Dia }\end{array}$ & $\begin{array}{c}\text { Portaria 518/04 } \\
\text { (V.P.M) }\end{array}$ & $\begin{array}{c}\text { Portaria 518/04 } \\
\text { (V.P.M) }\end{array}$ & $\begin{array}{l}\text { 2a Coleta } \\
\text { Dia }\end{array}$ & $\begin{array}{c}\text { Portaria 518/04 } \\
\text { (V.P.M) }\end{array}$ & $\begin{array}{c}\text { Portaria 518/04 } \\
\text { (V.P.M) }\end{array}$ \\
\hline $16 / 10 / 2012$ & $\begin{array}{c}\text { Ausência/100 ml } \\
\text { C. FECAL }\end{array}$ & $\begin{array}{c}\text { Ausência/100 ml } \\
\text { C. TOTAL }\end{array}$ & $21 / 10 / 2012$ & $\begin{array}{c}\text { Ausência/100 ml } \\
\text { C. FECAL }\end{array}$ & $\begin{array}{c}\text { Ausência/100 ml } \\
\text { C. TOTAL }\end{array}$ \\
\hline Amostra 01 & $100 \mathrm{UFC} / 100 \mathrm{ml}$ & $1000 \mathrm{UFC} / 100 \mathrm{ml}$ & Amostra 01 & & 1300 UFC/100 ml \\
\hline Amostra 02 & 400 UFC/100 ml & 2200 UFC/100 ml & Amostra 02 & $100 \mathrm{UFC} / 100 \mathrm{ml}$ & 1800 UFC/100 ml \\
\hline Amostra 03 & 800 UFC/100 ml & $2500 \mathrm{UFC} / 100 \mathrm{ml}$ & Amostra 03 & $500 \mathrm{UFC} / 100 \mathrm{ml}$ & 4000 UFC/100 ml \\
\hline Amostra 04 & & 2000 UFC/100 ml & Amostra 04 & 200 UFC/100 ml & 1900 UFC/100 ml \\
\hline Amostra 05 & $700 U F C / 100 \mathrm{ml}$ & 3600 UFC/100 ml & Amostra 05 & 500 UFC/100 ml & 2600 UFC/100 ml \\
\hline
\end{tabular}

V.P.M: valor máximo permitido. UFC/ml: unidade formadora de colônia por mililitro.

Tabela 3- Resultados análise de coliforme fecal e total, realizado no bloco 4.

\begin{tabular}{|c|c|c|c|c|c|}
\hline $\begin{array}{l}\text { 1a Coleta } \\
\text { Dia } \\
16 / 10 / 2012\end{array}$ & $\begin{array}{l}\text { Portaria 518/04 } \\
\text { (V.P.M) } \\
\text { Ausência/100 } \mathrm{ml} \\
\text { C. FECAL }\end{array}$ & $\begin{array}{l}\text { Portaria } 518 / 04 \\
\text { (V.P.M) } \\
\text { Ausência/100 ml } \\
\text { C. TOTAL }\end{array}$ & $\begin{array}{l}\text { 2a Coleta } \\
\text { pia } \\
21 / 10 / 2012\end{array}$ & $\begin{array}{l}\text { Portaria 518/04 } \\
\text { (V.P.M) } \\
\text { Ausência/100 ml } \\
\text { C. FECAL }\end{array}$ & $\begin{array}{l}\text { Portaria } 518 / 04 \\
\text { (V.P.M) } \\
\text { Ausência/100 ml } \\
\text { C. TOTAL }\end{array}$ \\
\hline Amostra 01 & 300 UFC/100 ml & 1200 UFC/100 ml & Amostra 01 & 100 UFC/100 ml & 1100 UFC/100 ml \\
\hline Amostra 02 & & 700 UFC/100 ml & Amostra 02 & 600 UFC/100 ml & 1300 UFC/100 ml \\
\hline Amostra 03 & & 1400 UFC/100 ml & Amostra 03 & 300 UFC/100 ml & 2100 UFC/100 ml \\
\hline Amostra 04 & 600 UFC/100 ml & 2800 UFC/100 ml & Amostra 04 & $400 \mathrm{UFC} / 100 \mathrm{ml}$ & 2200 UFC/100 ml \\
\hline Amostra 05 & $300 U F C / 100 \mathrm{ml}$ & 1100 UFC/100 ml & Amostra 05 & & 900 UFC/100 ml \\
\hline
\end{tabular}

V.P.M: valor máximo permitido. UFC/ml: unidade formadora de colônia por mililitro. 
Rev. Elet. em Gestão, Educação e Tecnologia Ambiental (e-ISSN: 2236-1170)

Tabela 4- Resultados análise de coliforme fecal e total, realizado no bloco 5.

\begin{tabular}{|c|c|c|c|c|c|}
\hline $\begin{array}{c}\text { 19. Coleta } \\
\text { Dia }\end{array}$ & $\begin{array}{c}\text { Portaria 518/04 } \\
\text { (V.P.M) }\end{array}$ & $\begin{array}{c}\text { Portaria 518/04 } \\
\text { (V.P.M) }\end{array}$ & $\begin{array}{l}\text { 2a Coleta } \\
\text { Dia }\end{array}$ & $\begin{array}{c}\text { Portaria 518/04 } \\
\text { (V.P.M) }\end{array}$ & $\begin{array}{c}\text { Portaria 518/04 } \\
\text { (V.P.M) }\end{array}$ \\
\hline $16 / 10 / 2012$ & $\begin{array}{l}\text { Ausência/100 ml } \\
\text { C. FECAL }\end{array}$ & $\begin{array}{l}\text { Ausência/100 ml } \\
\text { C. TOTAL }\end{array}$ & $21 / 10 / 2012$ & $\begin{array}{c}\text { Ausência/100 ml } \\
\text { C. FECAL }\end{array}$ & $\begin{array}{l}\text { Ausência/100 ml } \\
\text { C. TOTAL }\end{array}$ \\
\hline 01 & 100 UFC $/ 100 \mathrm{ml}$ & $1100 \mathrm{UFC} / 100 \mathrm{ml}$ & $\mathrm{Am}$ & 100 UFC & $800 \mathrm{U}$ \\
\hline a 02 & 700 UFC/100 ml & 200 & Amc & 1400 & $00 \mathrm{ml}$ \\
\hline Amostra 03 & & $1200 \mathrm{UFC} / 100 \mathrm{ml}$ & Amost & $400 \mathrm{UFC} / 100 \mathrm{ml}$ & $1600 \mathrm{UFC} / 100 \mathrm{ml}$ \\
\hline Amostra 04 & $100 \mathrm{UFC} / 100 \mathrm{ml}$ & $900 \mathrm{UFC} / 100 \mathrm{ml}$ & Amost & $100 u$ & $1300 \mathrm{UFC} / 100 \mathrm{ml}$ \\
\hline Amostra 05 & $300 \mathrm{UFC} / 100 \mathrm{ml}$ & $2100 \mathrm{UFC} / 100 \mathrm{ml}$ & Amostra 05 & $100 \mathrm{UFC} / 100 \mathrm{ml}$ & $2100 \mathrm{UFC} / 100 \mathrm{ml}$ \\
\hline Amostra 06 & 300 UFC $/ 100 \mathrm{ml}$ & $1600 \mathrm{UFC} / 100 \mathrm{ml}$ & Amostra 06 & & $800 \mathrm{UFC} / 100 \mathrm{ml}$ \\
\hline mostra 07 & $1500 \mathrm{UFC} / 100 \mathrm{ml}$ & $3100 \mathrm{UFC} / 100 \mathrm{ml}$ & Amostra 07 & $600 \mathrm{C}$ & $1400 \mathrm{UFC} / 100 \mathrm{ml}$ \\
\hline Amostra 08 & 200 UFC $/ 100 \mathrm{ml}$ & 800 UFC/100 ml & Amostra 08 & $400 \mathrm{UFC} / 100 \mathrm{ml}$ & 800 UFC/100 ml \\
\hline
\end{tabular}

V.P.M: valor máximo permitido. UFC/ml: unidade formadora de colônia por mililitro.

Tabela 5- Resultados análise de coliforme fecal e total, realizado no bloco 6.

\begin{tabular}{|c|c|c|c|c|c|}
\hline $\begin{array}{l}\text { 19 Coleta } \\
\text { Dia }\end{array}$ & $\begin{array}{c}\text { Portaria 518/04 } \\
\text { (V.P.M) }\end{array}$ & $\begin{array}{c}\text { Portaria 518/04 } \\
\text { (V.P.M) }\end{array}$ & $\begin{array}{l}\text { 2a Coleta } \\
\text { Dia }\end{array}$ & $\begin{array}{c}\text { Portaria 518/04 } \\
\text { (V.P.M) }\end{array}$ & $\begin{array}{c}\text { Portaria 518/04 } \\
\text { (V.P.M) }\end{array}$ \\
\hline $16 / 10 / 2012$ & $\begin{array}{l}\text { Ausência/100 ml } \\
\text { C. FECAL }\end{array}$ & $\begin{array}{l}\text { Ausência/100 ml } \\
\text { C. TOTAL }\end{array}$ & $21 / 10 / 2012$ & $\begin{array}{l}\text { Ausência/100 ml } \\
\text { C. FECAL }\end{array}$ & $\begin{array}{l}\text { Ausência/100 ml } \\
\text { C. TOTAL }\end{array}$ \\
\hline Amostra 01 & 200 UFC $/ 100 \mathrm{ml}$ & 800 UFC/100 ml & Amostra 01 & 100 UFC $/ 100 \mathrm{ml}$ & 1300 UFC/100 ml \\
\hline Amostra 02 & 300 UFC $/ 100 \mathrm{ml}$ & 900 UFC/100 ml & Amostra 02 & 400 UFC $/ 100 \mathrm{ml}$ & 1000 UFC/100 ml \\
\hline Amostra 03 & & 800 UFC/100 ml & Amostra 03 & & 1100 UFC/100 ml \\
\hline Amostra 04 & 500 UFC $/ 100 \mathrm{ml}$ & 2200 UFC/100 ml & Amostra 04 & & 1700 UFC/100 ml \\
\hline Amostra 05 & $100 \mathrm{UFC} / 100 \mathrm{ml}$ & 1900 UFC/100 ml & Amostra 05 & 200 UFC $/ 100 \mathrm{ml}$ & 1500 UFC/100 ml \\
\hline
\end{tabular}

V.P.M: valor máximo permitido. UFC/ml: unidade formadora de colônia por mililitro.

Através dos resultados apresentados nas tabelas 1, 2, 3, 4 e 5, pode-se observar que todos os Setores do município apresenta presença de coliforme fecal e total na água de poço; conforme Portaria 518/04, a água para consumo humano, incluindo fontes individuais como poços rasos não são permitidos a presença de coliforme fecal ou termo tolerantes em $100 \mathrm{ml}$ da água.

A (Figura 4) demonstra que na 1a coleta feita no dia 16/10/2012, identifica o bloco 03 (três) que corresponde aos Setores 02, 05 e 10, tem a maior média para coliforme fecal e total, e o bloco 06 (seis), que corresponde aos Setores 01, 02 e 09,tem a menor média para coliforme fecal e total. Já a 2 a coleta realizada no dia $21 / 10 / 2012$, não demonstra o mesmo seguimento da 1 a coleta, identificando o bloco 05 (cinco), que corresponde aos Setores 01, 03, 07 e 08, com a maior média para coliforme fecal, e o bloco 03 (três), continua com a maior média para coliforme total. O bloco 06 (seis), também continua com a menor média para coliforme fecal, o bloco 02 (dois), que corresponde aos Setores 03, 04 e 06, com a menor média para coliforme total. 


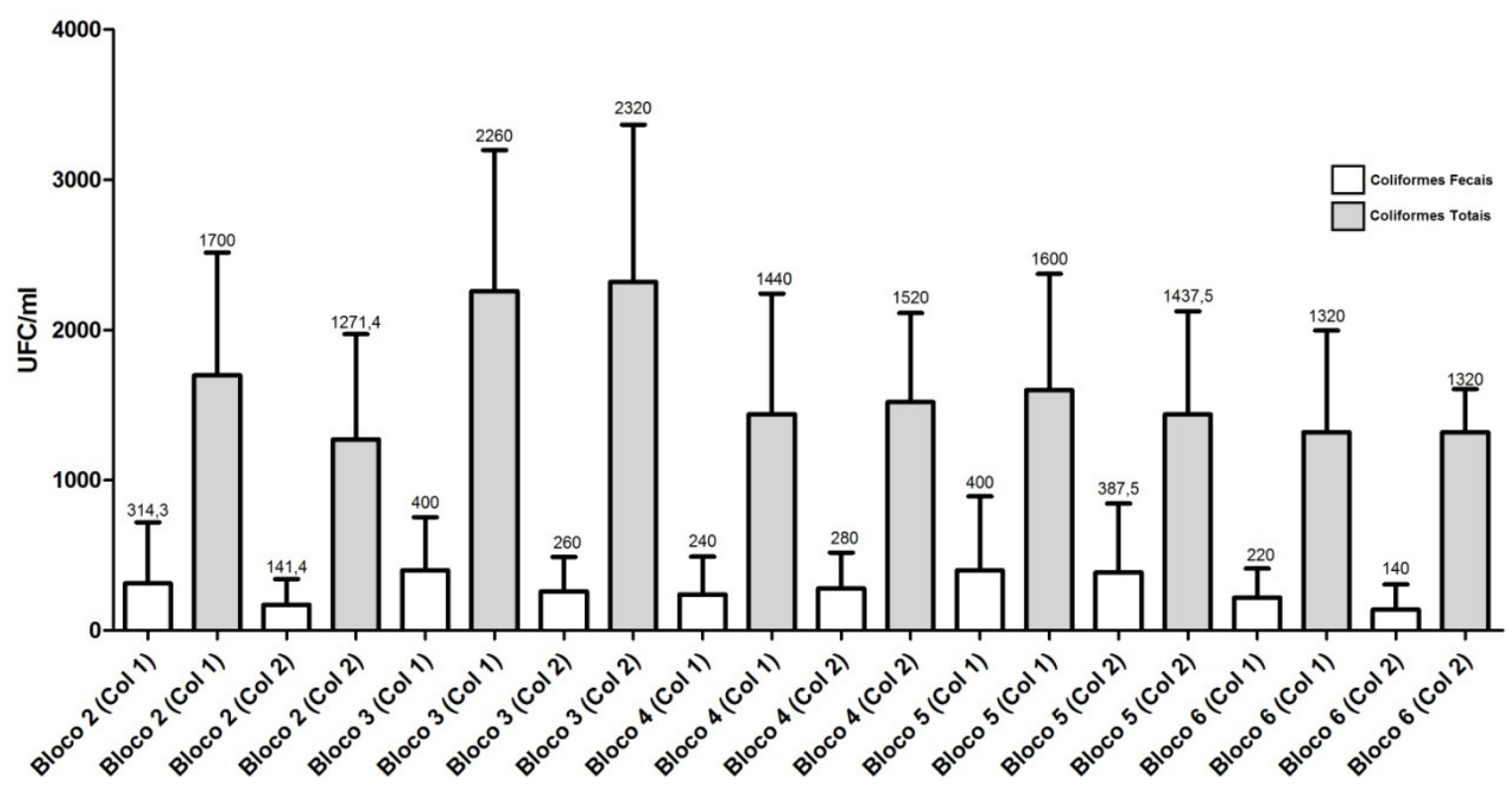

Figura 4: Média apresentada em cada bloco para presença de coliforme fecal e total.

A presença de coliformes nas amostras geralmente é decorrente da poluição de fezes humanas e animais (GONZALES et al., 1982).Isso demonstra a real situação de risco em que se encontram a população da área estudada frente ao lençol freático.Uma fonte de contaminação do aquífero freático é o uso de fossas negras e a inexistência de redes coletoras de esgoto (BRASIL, 2006).

Já Vasconcelos (2009), em seu trabalho de estudo físico-químico e microbiológico de águas de poços tubulares da cidade de Manaus, realizando também trinta coletas, observou a variação dos testes que foram mais elevadas no período de seca, que corresponde aos meses de Julho a Outubro.

Segundo Harwood et al., (2000), outro grande problema que relaciona a contaminação da água, é o desenvolvimento de resistência dos microrganismo aos medicamentos antimicrobianos, que quando a contaminação tem origem humana os microrganismos isolados apresentam resistência aos antibióticos mais utilizados pela população, como ampicilina, amoxicilina e cefalotina.

O consumo de água que atenda os padrões de potabilidade constitui uma ação de política pública de prevenção de doenças e mortalidades; as águas que não atendam este padrão recomendável precisam ser evitadas, através de informações e promoções de políticas públicas que garantam o acesso á água adequada ao consumo humano (SILVA et al., 2003). Essas informações e esclarecimentos a população podem ser promovidas através de campanhas do poder público federal, estadual e municipal, secretárias de educação e meio ambiente como também a sociedade civil organizada, através de palestras comunitárias e escolares, principalmente no que diz respeito à preservação e uso de água de poço, quanto aos riscos e perigos atuais e futuros (VASCONCELOS, 2006).

Segundo Machado (2003), o aperfeiçoamento do sistema brasileiro de recursos hídricos depende da nossa capacidade de exercer a cidadania, tornando um estímulo ao compromisso de todos de agir sempre em prol do bem-estar das futuras gerações. 
Rev. Elet. em Gestão, Educação e Tecnologia Ambiental (e-ISSN: 2236-1170)

\section{CONCLUSÃO}

Através das análises realizadas nas amostras coletadas em poços rasos da zona urbana do município de Buritis, apontam a contaminação do lençol freático por coliforme fecal e total em todos os blocos, não atendendo os padrões de potabilidade recomendado na Portaria 518/04, e o consumo humano representa risco e agravos à saúde.

É importante ressaltar que esse é o primeiro estudo de análise de qualidade de água realizado no município e a não presença de Salmonella pode estar sendo subestimado. Segundo REIS (et al, 2001) pode haver reações cruzadas com as enterobactérias, pois existe uma estreita relação antigênicas somática entre Salmonellae outras enterobactérias como Escherichia coli, como também pode haver ausência nas reações falso-positivo; sendo indicado estudos futuros, com o intuito de uma maior amostragem dos resultados e observação de variação sazonal para uma melhor compreensão destes.

\section{REFERÊNCIAS}

BLANK et al. Caracterização Físico-Química e Microbiológica de Água de Poços Rasos do Bairro Três Vendas, Pelotas-RS. XII ENPOS-II Mostra Científica, 2010.

BRASIL- Ministério da Saúde; Secretaria de Vigilância em Saúde; Vigilância e controle da qualidade da água para consumo humano. Brasília-DF; 2006. (Série B. Textos Básicos de Saúde). 212 p.

BRASIL, Ministério da Saúde. Fundação Nacional de Saúde. Portaria. № 518 de 25 de março de 2004; Estabelece os procedimentos e responsabilidades relativos ao controle e vigilância da qualidade da água para consumo humano e seu padrão de potabilidade, e dá outras providências. Disponível em: <http://dtr2001.saude.gov.br/sas/PORTARIAS/Port2004/GM/GM-518.htm> acesso em: 28 de Set 2012.

BRASIL. Ministério da Saúde. Agência Nacional de Vigilância Sanitária. Resolução RDC n. 54, de 15 de junho de 2000.

BRASIL. Ministério da saúde. Manual prático de análise de água. 3a ed. rev. Brasília: Fundação Nacional de Saúde, 2009.

BRASIL. Ministério do Planejamento: Instituto Brasileiro de Geografia e Estatística - IBGE. Cidade de Buritis, Estado de Rondônia. 2010. Disponível em: <http://www.ibge.gov.br/cidadesat/link. php?uf=ro> acesso em: 23 de Set 2012.

CETESB- Companhia de Tecnologia de Saneamento Ambiental. Procedimento Para Coleta de Amostras de Água. 1987.

DUARTE, P.B. Microrganismo indicadores de poluição fecal em recursos hídricos. Monografia (Instituto de Ciências Biomédicas da Universidade Federal de Minas Gerais), 2011.

FREITAS, M.B; BRILHANTE, O.M; ALMEIDA, L.M. Importância da análise de água para a saúde pública em duas regiões do Estado do Rio de Janeiro: enfoque para coliformes fecais, nitrato e alumínio. Cad. Saúde Pública, vol.17, n.3, p. 651-660, 2001. 
Rev. Elet. em Gestão, Educação e Tecnologia Ambiental (e-ISSN: 2236-1170)

GONZALEZ; R. G; TAYLOR; M. L; ALFARO; G. Estudo bacteriano del agua de consumo enunacomunidad Mexicana. Bol Oficina Sanit Panam, v.93, p. 127-40, 1982.

HARWOOD; V. J; WHITLOCK; J; WITHINGTON; V; Classification of Antibiotic Resistance Patterns of Indicator Bacteria by Discriminant Analysis: Use in Predicting the Source of Fecal Contamination in Subtropical Waters. Appl Environ Microbiol, v. 66, n.9, p.3698-3704, 2000.

MACHADO. C.J.S. Recursos Hídricos e Cidadania no Brasil: Limites, Alternativas e Desafios. Ambiente \& Sociedade, v. 6 n‥ 2 jul./dez., 2003.

MANUAL. Manual de Vigilância Ambiental e Instruções de Coleta Para Ensaios Laboratoriais. Disponível em: <http://ebookbrowse.com/arq-203-arq-762-manual-vig-ambiental-doc-d41313767> acesso em 19 de Out 2012.

REIS, R.B; MAMIZUKA, E.M; FRANCO, B.D.G.M. Produção de imunorreagentes para uso em um teste imunoenzimático de deteç̧ão de salmonella em alimentos. Ciênc. Tecnol. Aliment, vol.21, n.3, p. 261-266, 2001.

RONDEN; $F$ et al. Monitoramento microbiológico de águas subterrâneas em cidades do Extremo Oeste de Santa Catarina. Ciência \& Saúde Coletiva, vol. 14, n. 6, p. 2199-2203, 2009

SILVA, L.M; SOUZA, E.H; ARREBOLA, T.M; JESUS, G.A. Ocorrência de um surto de hepatite A em três bairros do município de Vitória (ES) e sua relação com a qualidade da água de consumo humano. Ciênc. saúde coletiva, vol.14, n.6, p. 2163-2167, 2009.

SILVA, R.C.A; ARAUJO, T.M. Qualidade da água do manancial subterrâneo em áreas urbanas de Feira de Santana (BA). Ciênc. saúde coletiva, vol.8, n.4, p. 1019-1028, 2003.

VASCONCELOS; T.A. Estudo Físico-Químico e Microbiológico de Águas de poços Tubulares da Cidade de Manaus. Dissertação de Mestrado (Universidade Federal do Amazonas), 2006.

ZAMPIERON; S. L. M; VIEIRA; J. L. A. Poluição da água. Disponível em <http//educar.sc.usp.br/biologia/textos/m_a_txt5.html> acessado em 30 de Out 2012. 